\title{
Dissolution rates of limestones of different sources
}

\author{
Shin-Min Shih*, Jyh-Ping Lin, Gwo-Yuan Shiau \\ Department of Chemical Engineering, National Taiwan University, Taipei, 106 Taiwan
}

Received 20 January 2000; received in revised form 26 April 2000; accepted 1 May 2000

\begin{abstract}
The dissolution characteristics of limestones from six sources in Taiwan have been studied by using the pH-stat method in a stirred tank at $60^{\circ} \mathrm{C}, \mathrm{pH}$ values of 4 and 6 , stirrer speeds of 500-1000 rpm, and a particle size of 75-125 $\mu \mathrm{m}$ aperture width. The dissolution rates of the limestones were found to be controlled by the mass transfer of hydrogen ions with chemical reactions in the liquid film surrounding the limestone particle. The measured value of mass transfer coefficient increases with an increasing $\mathrm{pH}$ value and stirrer speed and remains constant with particle size. For the six limestones at the same particle size, the measured dissolution rates per unit area are the same due to the mass-transfer control kinetics; however, the time taken to reach a certain fraction of dissolution is proportional to the molar concentration of the soluble species in the limestone and the initial particle size. (C) 2000 Elsevier Science B.V. All rights reserved.
\end{abstract}

Keywords: Limestone; Dissolution; Flue gas desulfurization

\section{Introduction}

The wet type limestone scrubbing process is the most commonly used flue gas desulfurization (FGD) process for thermal power plants. In this process, limestone slurry is used to absorb $\mathrm{SO}_{2}$ from the flue gas. Limestone particles in the slurry dissolve and react with the absorbed $\mathrm{SO}_{2}$ to from solid products. Accurately evaluating the dissolution rate of limestone is important in the development and the efficient operation of the $\mathrm{SO}_{2}$ wet scrubbing system.

The main constituent of limestone is calcite $\left(\mathrm{CaCO}_{3}\right)$. Many studies on the dissolution of calcite or limestone have been carried out so far. The most significant previous

\footnotetext{
* Corresponding author. Tel.: +886-2-23633974; fax: +886-2-23623040.

E-mail address: smshih@ccms.ntu.edu.tw (S.-M. Shih).
} 
work on calcite dissolution has been done under seawater conditions by geochemists. Plummer et al. [1] reviewed this work and concluded that the rates were controlled by hydrogen ion diffusion below $\mathrm{pH} 5$ and by surface reaction kinetics above $\mathrm{pH} 5$. Plummer et al. [1] introduced no factors to account for the specific geological characteristics of the limestone samples. However, some studies under conditions typical of FGD have given apparent effects of limestone type and particle size. Drehmel [2] measured the dissolution rates of various types of limestone in acid media and showed the considerable differences in their dissolution rates. He also found a strong effect of particle size. Chan and Rochelle [3] measured the dissolution rate of reagent calcite as a function of $\mathrm{pH}$, temperature, $\mathrm{CO}_{2}$ partial pressure, and solution composition. They modeled the dissolution rate by mass transfer with equilibrium acid-base reactions and a finite-rate homogeneous reaction of $\mathrm{CO}_{2}$ and $\mathrm{H}_{2} \mathrm{O}$. Toprac and Rochelle [4] extended the work of Chan and Rochelle (1982) to commercial limestones of different types and grinds by modifying the mass-transfer model to account for the effect of solution turbulence on large particles. They found that particle size distribution is the most important reactivity characteristic of a ground limestone of reasonable purity. The work by Gage and Rochelle [5] showed that in the presence of sulfite and other inhibitors of limestone dissolution, the dissolution rate is not simply mass transfer controlled and it can be a strong function of limestone type. Ukawa et al. [6] reported that their experimental results for the dissolution of limestones of different compositions and size distributions are in good agreement with the predictions of the model proposed by Toprac and Rochelle. Ahlbeck et al. [7,8] proposed a sequential method for measuring the reactivity of limestone.

Since the dissolution of a limestone may be affected by its geological origin and composition, there is a need to study the dissolution characteristics of local limestones to provide the basic data for the design and operation of local FGD facilities.

In this study, the dissolution rates of limestones from six major sources in Taiwan were measured and compared for particles of the same initial size range without the presence of sulfite and other inhibitors by using the $\mathrm{pH}$-stat method.

\section{Mathematical model}

When a strong acid is added to a stirred limestone slurry, the acid completely dissociates and hydrogen ions are formed. The limestone in water dissolves to a low degree according to

$$
\mathrm{CaCO}_{3} \rightleftharpoons \mathrm{Ca}^{2+}+\mathrm{CO}_{3}^{2-} \text {. }
$$

The carbonate ions react with the hydrogen ions to form $\mathrm{HCO}_{3}^{-}, \mathrm{CO}_{2}(\mathrm{aq})$ and $\mathrm{CO}_{2}(\mathrm{~g})$ as follows

$$
\begin{aligned}
& \mathrm{CO}_{3}^{2-}+\mathrm{H}^{+} \rightleftharpoons \mathrm{HCO}_{3}^{-} \\
& \mathrm{HCO}_{3}^{-}+\mathrm{H}^{+} \rightleftharpoons \mathrm{CO}_{2}(\mathrm{aq})+\mathrm{H}_{2} \mathrm{O} \\
& \mathrm{CO}_{2}(\mathrm{aq}) \rightleftharpoons \mathrm{CO}_{2}(\mathrm{~g}) .
\end{aligned}
$$


When carbonate ions are consumed by reaction (2), more limestone dissolves. Most researchers found that reaction (1) is very fast, and some reported that the rate depends on the property of limestone [2,7,8]. Reaction (2) is instantaneous [9]; its equilibrium constant is very large, $2.27 \times 10^{10} \mathrm{~m}^{3} / \mathrm{kg}$ mol at $298 \mathrm{~K}$, thus almost all the carbonate ions are converted by this reaction in acidic solution.

Since the rates of the reactions involved are fast, the dissolution rate of limestone is affected by the mass transfer of the reacting species. A complete mass transfer model involving the diffusion of all possible species was presented by Wallin and Bjerle [10]. Their results showed that the diffusion of hydrogen ions is the dominant process. Toprac and Rochelle [4] and Ukawa et al. [6] found that the dissolution rate is primarily controlled by the mass transfer of hydrogen ions from the liquid bulk to the limestone surface through the boundary layer surrounding the limestone particle. Ahlbeck et al. [8] proposed that the dissolution rate is controlled by the mass transfer of the hydrogen ion and its reaction at the limestone surface.

Assuming that the limestone particle is nonporous and spherical and dissolves according to shrinking-core behavior, the rate per unit surface area of the particle can be expressed by

$$
-\rho_{\mathrm{m}} \frac{d R}{d t}=k\left(C_{\mathrm{b}}-C_{\mathrm{s}}^{*}\right)
$$

where $\rho_{\mathrm{m}}$ is the molar concentration of $\mathrm{CaCO}_{3}$ and $\mathrm{MgCO}_{3}$ in the limestone, $R$ is the particle radius, $t$ is the time, $k$ is the dissolution rate constant, $C_{\mathrm{b}}$ is the bulk concentration of hydrogen ions, $C_{\mathrm{s}}^{*}$ is the surface concentration of hydrogen ions if the surface reaches equilibrium. The dissolution rate constant $k$ is defined by

$$
\frac{1}{k}=\frac{1}{k_{\mathrm{L}}}+\frac{1}{k_{\mathrm{r}}}
$$

where $k_{\mathrm{L}}$ is the mass transfer coefficient and $k_{\mathrm{r}}$ is the rate constant of the surface reaction. For limestone dissolution in acidic solution, $C_{\mathrm{b}}$ is much greater than $C_{\mathrm{s}}^{*}$, and $C_{\mathrm{s}}^{*}$ can be taken as zero in Eq. (5) [8]. At constant $C_{\mathrm{b}}$, if the mass-transfer coefficient $k_{\mathrm{L}}$ is independent of particle size or for the period in which the particle size change is not appreciable, Eq. (5) can be integrated to yield

$$
t=\frac{\rho_{\mathrm{m}} R_{0}}{k C_{\mathrm{b}}}\left(1-\frac{R}{R_{0}}\right)
$$

where $R_{0}$ is the initial particle radius. The independence of $k_{\mathrm{L}}$ on particles size under the experimental conditions of this study is justified by subsequent discussion in Section 4.

The particle radius $R$ is related to the fraction of dissolution $X$ of the particle by

$$
\frac{R}{R_{0}}=(1-X)^{\frac{1}{3}}
$$


Substituting Eq. (8) into Eq. (7) yields

$$
t=\frac{\rho_{\mathrm{m}} R_{0}}{k C_{\mathrm{b}}}\left[1-(1-X)^{\frac{1}{3}}\right]
$$

If the limestone sample is composed of particles of uniform size, both the dissolution rate per unit surface area and the fraction of dissolution of the sample should be the same as those of a single particle at the same dissolution time, i.e.,

$$
\begin{aligned}
& \frac{1}{A_{\mathrm{S}}} \frac{d m}{d t}=\rho_{\mathrm{m}} \frac{d R}{d t} \\
& 1-\frac{m}{m_{0}}=X
\end{aligned}
$$

where $m_{0}$ and $m$ is the total moles of $\mathrm{CaCO}_{3}$ and $\mathrm{MgCO}_{3}$ in the sample before dissolution and at dissolution time $t$, respectively; and $A_{\mathrm{S}}$ is the total surface area of the sample. $A_{\mathrm{S}}$ can be calculated from its initial value, $A_{\mathrm{SO}}$, by

$$
A_{\mathrm{S}}=A_{\mathrm{SO}}\left(\frac{m}{m_{0}}\right)^{2 / 3} .
$$

\section{Experimental}

Batch dissolution rates for various limestones were measured at constant $\mathrm{pH}$ by using a $\mathrm{pH}$-stat apparatus. The $\mathrm{pH}$ was automatically controlled to \pm 0.02 units by titrating with $0.1 \mathrm{M} \mathrm{HCl}$. The limestone dissolution rate was related to the titration rate by the stoichiometry

$$
\mathrm{CaCO}_{3}+2 \mathrm{HCl} \rightleftharpoons \mathrm{CaCl}_{2}+\mathrm{H}_{2} \mathrm{O}+\mathrm{CO}_{2}
$$

The relative change of calcium concentration in the reactor was minimized by dissolving $0.15 \mathrm{~g}$ of $\mathrm{CaCO}_{3}$ in 0.251 of $0.1 \mathrm{M}$ dissolved $\mathrm{CaCl}_{2}$. The cumulative dissolution was determined directly from a recording of $\mathrm{HCl}$ volume added vs. time. The fraction of dissolution $X$ was obtained by the ratio of the $\mathrm{HCl}$ volume added to that required for complete dissolution.

The experimental apparatus is shown in Fig. 1. Agitation was provided by a three-blade propeller rotating at 500-1100 rpm to fully fluidize the sample. The reactor temperature was controlled to $\pm 0.2^{\circ} \mathrm{C}$ by a water jacket. The experiments were performed at $60^{\circ} \mathrm{C}$ and $\mathrm{pH} 4$ and 6 .

Natural limestones from six different mines in Taiwan were provided by cement companies. The contents of $\mathrm{CaCO}_{3}$ in these limestones are from 74 to $95 \mathrm{wt} \%$, and 


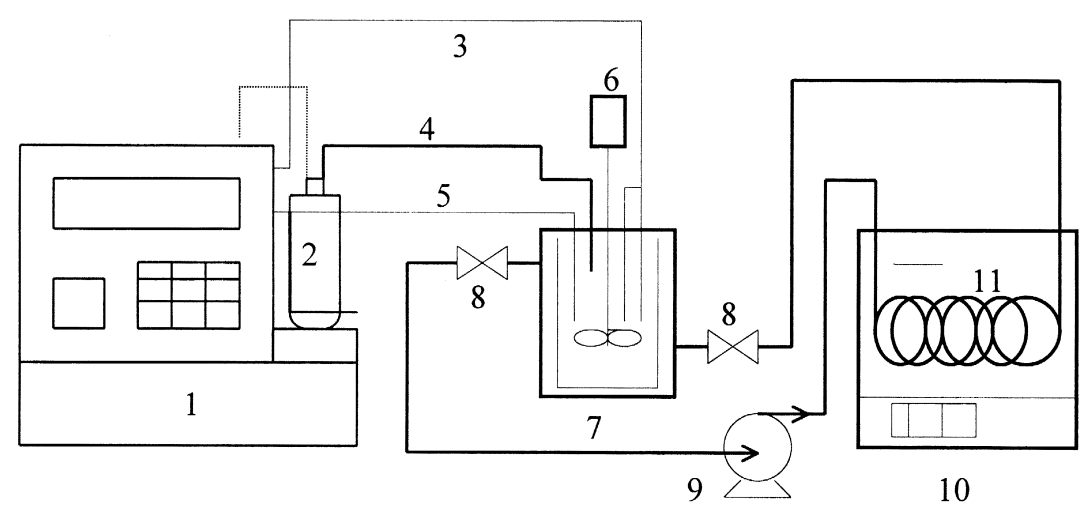

Fig. 1. Schematic of experimental apparatus. (1) Autotitrator, (2) $\mathrm{HCl}$ bottle, (3) $\mathrm{pH}$ probe wire, (4) $\mathrm{HCl}$ titrant line, (5) temperature compensation electrode wire, (6) stirrer, (7) reactor, (8) valve, (9) microtube pump, (10) water bath, (11) copper coil.

$\mathrm{MgCO}_{3}$ from 0.8 to $3.2 \mathrm{wt}$ \% (Table 1). The percent available for dissolution in a given sample was taken to be the sum of $\mathrm{CaCO}_{3}$ and $\mathrm{MgCO}_{3}$ contents.

The raw sample were crushed, ground, and sieved to different size ranges. Samples obtained between 75 and $125 \mu \mathrm{m}$ apertures were used in this study. These samples were washed with ethanol to remove adhered fine particles. Their size distributions were measured by using a Coulter LS-230. The results showed that the portion of fine particles is negligible. The volume-mean particle diameters of these six samples were not exactly the same, but varied from 102.4 to $127.6 \mu \mathrm{m}$ (Table 1).

The bulk density, porosity, and BET surface area of each type of limestone were measured and are listed in Table 1. The total molar concentration of $\mathrm{CaCO}_{3}$ and $\mathrm{MgCO}_{3}$ for each limestone, $\rho_{\mathrm{m}}$, is also shown in Table 1, which was calculated from the bulk density and the weight fractions of $\mathrm{CaCO}_{3}$ and $\mathrm{MgCO}_{3}$ for the limestone. The limestomes from eastern part of Taiwan (Shin-Cherng, Tay-Bair Mt., Her-Pyng) have higher $\rho_{\mathrm{m}}$ than those from western part (Dah-Gang Mt., Chyh-Ke Mt., Bann-Pyng Mt.).

Table 1

Soluble contents and physical properties of limestones

\begin{tabular}{llllllll}
\hline Source & $\begin{array}{l}\mathrm{CaCO}_{3} \\
(\mathrm{wt} \%)\end{array}$ & $\begin{array}{l}\mathrm{MgCO}_{3} \\
(\mathrm{wt} \%)\end{array}$ & $\begin{array}{l}d \\
(\mu \mathrm{m})\end{array}$ & $\begin{array}{l}\rho_{\mathrm{b}} \\
\left(\mathrm{g} / \mathrm{cm}^{3}\right)\end{array}$ & $e$ & $\begin{array}{l}S_{\mathrm{g}} \\
\left(\mathrm{m}^{2} / \mathrm{g}\right)\end{array}$ & $\begin{array}{l}\rho_{\mathrm{m}} \\
\left(\mathrm{mol}^{2} / \mathrm{cm}^{3}\right)\end{array}$ \\
\hline Tay-Bair Mt. & 94.8 & 1.1 & 102.4 & 2.579 & 0.05 & 0.4 & 0.02478 \\
Her-Pyng & 92.7 & 2.7 & 112.2 & 2.497 & 0.09 & 0.7 & 0.02395 \\
Shin-Cherng & 95.0 & 3.2 & 118.2 & 2.619 & 0.04 & 0.2 & 0.02586 \\
Chyh-Ke Mt. & 77.5 & 1.1 & 125.4 & 2.603 & 0.05 & 0.7 & 0.02051 \\
Dah-Gang Mt. & 81.0 & 0.8 & 117.5 & 2.516 & 0.08 & 1.6 & 0.02060 \\
Bann-Pyng Mt. & 74.0 & 1.1 & 127.6 & 2.452 & 0.10 & 2.5 & 0.01846 \\
\hline
\end{tabular}




\section{Results and discussion}

As can be seen from Table 1, the limestones have very small porosities $(\leq 0.1)$ and thus can be considered as nonporous. Their BET specific surface areas, varying from 0.2 to $2.5 \mathrm{~m}^{2} / \mathrm{g}$, are much larger than that calculated for a nonporous spherical particle with the same diameter. The larger measured specific surface area is attributed to the adhered fines, the irregular particle shape, and the uneven and rough particle surface, as can be seen from the SEM micrograph of limestone particles.

During the dissolution experiment, the fine particles and the rough surface layer dissolved first and gave a short initial period of high dissolution rate. The $\mathrm{HCl}$ volume added during this period was not included in the $\mathrm{HCl}$ volume added vs. time data for dissolution rate calculation. This initial $\mathrm{HCl}$ volume was very small compared to the total volume required for complete dissolution. As the dissolution proceeded, the particle shape became rounder and the particle surface became smoother.

\subsection{Dissolution at $\mathrm{pH} 4$}

Fig. 2 shows the data of $\mathrm{HCl}$ volume added vs. time at $60^{\circ} \mathrm{C}$ and $\mathrm{pH} 4$ for Tai-Bair Mt. and Bann-Pyng Mt. Other types of limestone gave similar plots. It can be observed that the dissolution rate is higher at higher stirrer speed. This indicates that the dissolution rate was affected by mass transfer.

Fig. 3 shows the plot of $\left[1-(1-X)^{1 / 3}\right]$ vs. time for Tai-Bair Mt. limestone. One can see that the data points for each stirrer speed can be represented by a straight line up to the corresponding $X$ value of about 0.97 or the $R / R_{0}$ value of about 0.3 . This result indicates that Eq. (9) is valid not only for the early period of dissolution, but also for the latter period in which the reduction of particle size is appreciable. This result also implies that the dissolution rate constant $k$ is insensitive to particle size.

According to Eq. (6), $k$ is a function of $k_{\mathrm{L}}$ and $k_{\mathrm{r}}$. Thus the insensitivity of $k$ to particle size is due to either that $k_{\mathrm{r}}$, which is independent of particle size, is a lot smaller than $k_{\mathrm{L}}$ and $k \approx k_{\mathrm{r}}$ or that $k_{\mathrm{L}}$ is a weak function of particle size. Since $k_{\mathrm{L}}$ is also a function of stirrer speed and the slope of the straight line in Fig. 3 increases with increasing stirrer speed, the insensitivity of $k$ to particle size is due to the fact that $k_{\mathrm{L}}$ is a weak function of particle size.

The liquid phase mass transfer coefficient for particles suspended in stirred tanks has been measured by many investigators. Correlation given by Calderbank and Moo-Young [11] shows $k_{\mathrm{L}}$ to be independent of particle size if the mass transfer is due to turbulence in the surrounding fluid. According to the terminal velocity-slip velocity theory, Harriott [12] found that the mass transfer coefficient must increase with decreasing diameter for very small particles, but should be nearly independent of particle size over the range of 100-1000 $\mu \mathrm{m}$. Correlations presented by Brian et al. [13] and Levins and Glastonbury [14] show that $k_{\mathrm{L}}$ is affected by particle diameter, specific agitation power, and Schmidt number and that $k_{\mathrm{L}}$ increases as particle diameter decreases, but the effect of particle diameter on $k_{\mathrm{L}}$ is small at high values of particle diameter, specific agitation power, and Schmidt number. 

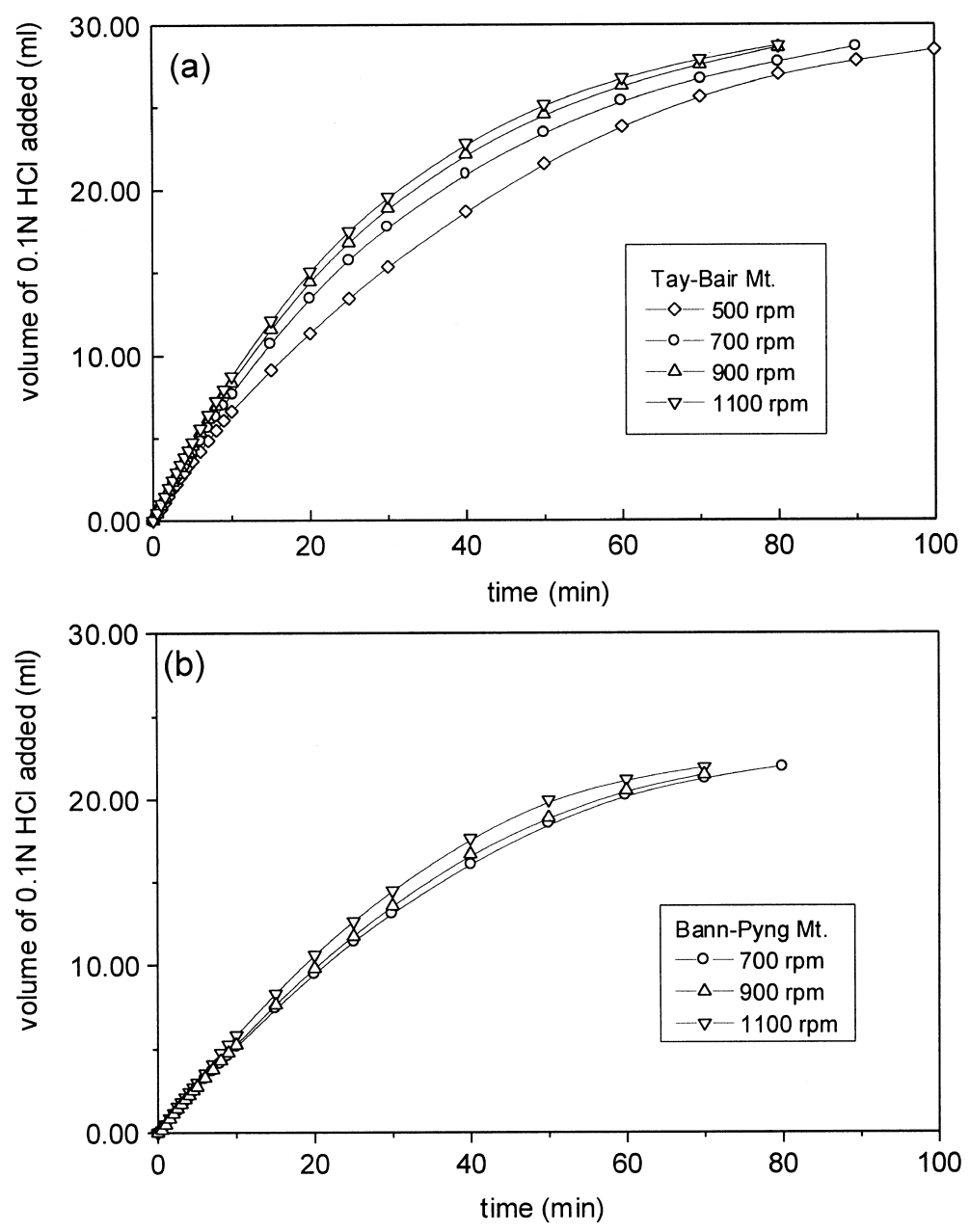

Fig. 2. Titration curves for limestones at $\mathrm{pH} 4$ and $60^{\circ} \mathrm{C}$ for $0.15 \mathrm{~g}$ limestone in $250 \mathrm{ml} 0.1 \mathrm{M} \mathrm{CaCl}_{2}$. (a) Tai-Bair Mt., (b) Bann-Pyng Mt.

In the present study, the stirrer speed, being in the range of 500-1000 rpm, is high, the particles were fully suspended, and the particle size considered, being in the range of about 100 (initial diameter) to $30 \mu \mathrm{m}$ (final diameter), is not small; thus the agitation condition should be in the range where the effect of particle size on mass transfer is rather small.

According to Eq. (9), the value of $k$ can be calculated from the slope of the straight line in Fig. 3. The value of $k$ obtained for each stirrer speed, $\omega$, is shown in Fig. 4. It is seen that there is a linear relation between $\ln k$ and $\ln \omega$ and $k$ varies as the 0.43 power of the stirrer speed. This result is in accordance with the correlation between $k_{\mathrm{L}}$ and $\omega$ reported by previous works. For example, Harriott [12] reported that the exponent of $\omega$ 


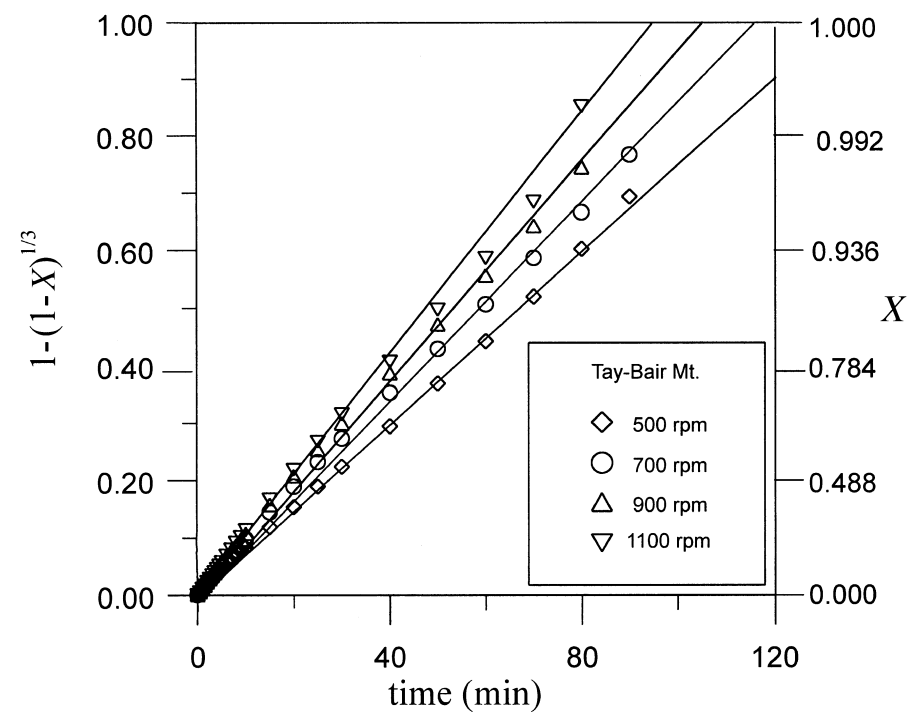

Fig. 3. Plot of $1-(1-X)^{1 / 3}$ vs. time for Tai-Bair Mt. limestone dissolution at $\mathrm{pH} 4$ and $60^{\circ} \mathrm{C}$ for $0.15 \mathrm{~g}$ limestone in $250 \mathrm{ml} 0.1 \mathrm{M} \mathrm{CaCl}_{2}$.

is in the range of $0.3-0.5$. According to the correlation given by Levins and Glastonbury [14], $k_{\mathrm{L}}$ is proportional to the 0.21 power of the specific agitation power. Since the specific agitation power increases as the two to three power of the stirrer speed [15], the exponent of $\omega$ can be estimated to be in the range of $0.41-0.62$.

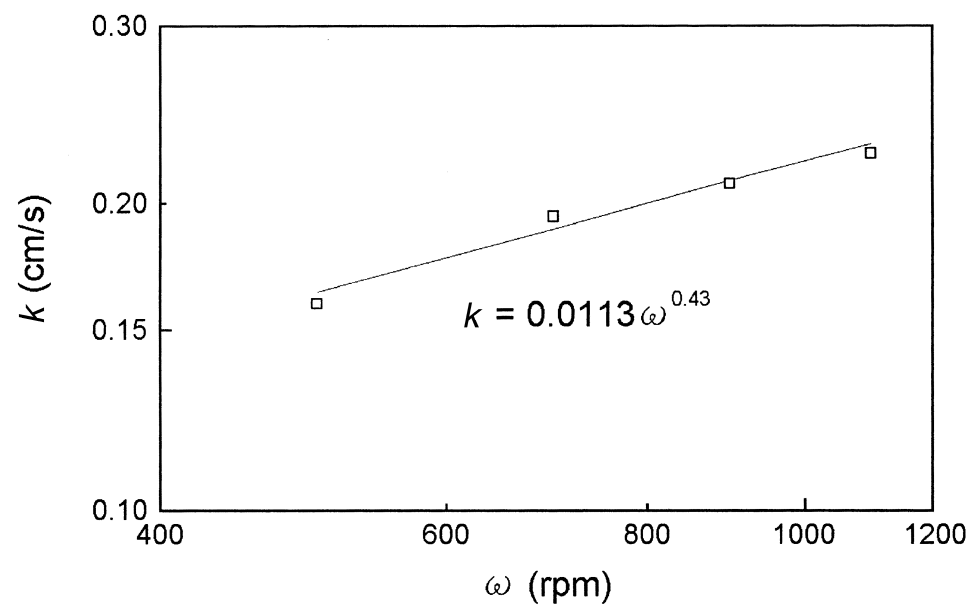

Fig. 4. Rate constant $k$ vs. stirrer speed for Tai-Bair Mt. limestone dissolution at $\mathrm{pH} 4$ and $60^{\circ} \mathrm{C}$ for $0.15 \mathrm{~g}$ limestone in $250 \mathrm{ml} 0.1 \mathrm{M} \mathrm{CaCl}_{2}$. 
Table 2

Dissolution rate constants for limestones of different sources (mean particle diameters: 102-128 $\mu \mathrm{m}$, sample weight: $0.15 \mathrm{~g}$, liquid volume: $250 \mathrm{ml} 0.1 \mathrm{M} \mathrm{CaCl}_{2}$ solution, stirrer speed: $1100 \mathrm{rpm}, \mathrm{pH}$ : 4.0 and 6.0 , temperature: $60^{\circ} \mathrm{C}$ )

\begin{tabular}{lll}
\hline Source & \multicolumn{2}{l}{ Rate constant $k(\mathrm{~cm} / \mathrm{s})$} \\
\cline { 2 - 3 } & $\mathrm{pH}=4.0$ & $\mathrm{pH}=6.0$ \\
\hline Tay-Bair Mt. & 0.223 & 0.846 \\
Her-Pyng & 0.246 & 0.940 \\
Shin-Cherng & 0.253 & 0.688 \\
Chyh-Ke Mt. & 0.223 & 0.836 \\
Dah-Gang Mt. & 0.208 & 0.908 \\
Bann-Pyng Mt. & 0.195 & 0.981 \\
Average & 0.225 & 0.867 \\
SD & 0.022 & 0.103 \\
\hline
\end{tabular}

Basing upon the observed behavior of $k$ in response to the changes of particle size and stirrer speed, one may conclude that $k$ is essentially equal to $k_{\mathrm{L}}$ and the dissolution of limestone is controlled by the mass transfer of hydrogen ions. The same conclusion holds for other types of limestone.

Table 2 gives the values of $k$ measured at $\mathrm{pH} 4$ and a stirrer speed of $1100 \mathrm{rpm}$ for the six limestones. The $k$ values vary from 0.195 to $0.253 \mathrm{~cm} / \mathrm{s}$ among the six limestones. The variation in $k$ value, however, has no consistent relation with the limestone property; therefore, it is attributed to the experimental errors. The average value of $k$ for the six limestones is $0.225 \mathrm{~cm} / \mathrm{s}$ with a standard deviation of $10 \%$ of the average $k$ value.

\subsection{Dissolution at $\mathrm{pH} 6$}

The dissolution rates of the limestones at pH 6 and $1100 \mathrm{rpm}$ stirrer speed were very slow. Less than $20 \%$ of limestone was dissolved in $140 \mathrm{~min}$. The corresponding particle-size change was estimated to be less than 7\%. Therefore, Eq. (9) can be employed to describe the dissolution of limestone. As shown in Fig. 5, where the data are plotted in terms of $1-(1-X)^{1 / 3}$ vs. time, the data for each limestone can be represented by a straight line.

The value of $k$ calculated from the slope of the straight line corresponding to each limestone is also show in Table 2. The $k$ values for limestone also differ somewhat from one another; but the variation in $k$ value also shows no relation with the limestone property or the value obtained at $\mathrm{pH} 4$, and therefore is caused by the experimental error. The average value of $k$ for the limestones is $0.867 \mathrm{~cm} / \mathrm{s}$ with a standard deviation of $12 \%$ of the average $k$ value. The independence of $k$ value on the source of limestone indicates that the dissolution of limestone at $\mathrm{pH} 6$ is also controlled by mass transfer.

According to Eq. (9), the time taken for a limestone to reach a certain fraction of dissolution is proportional to its $\rho_{\mathrm{m}} R_{0}$ if $k C_{\mathrm{b}}$ is kept constant. This relationship can be confirmed by comparing the experimental data for all types of limestone. As can be seen from Fig. 5, except for Her-Pyng limestone, the limestone with larger value of $\rho_{\mathrm{m}} R_{0}$ 


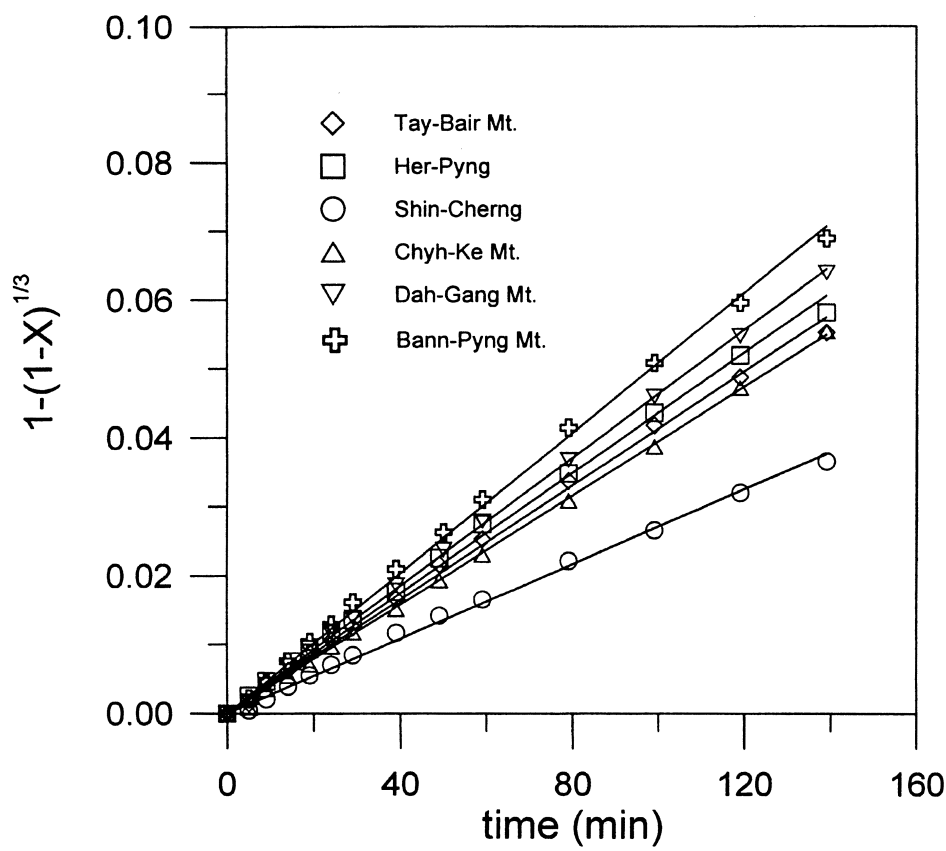

Fig. 5. Plot of $1-(1-X)^{1 / 3}$ vs. time for limestone dissolution at $\mathrm{pH} 6,1100 \mathrm{rpm}$, and $60^{\circ} \mathrm{C}$ for $0.15 \mathrm{~g}$ limestone in $250 \mathrm{ml} 0.1 \mathrm{M} \mathrm{CaCl}_{2}$.

(see Table 1) takes longer time to reach the same fraction of dissolution. The exception of Her-Pyng limestone may be due to the fact that the actual $\rho_{\mathrm{m}} R_{0}$ is smaller than that calculated from Table 1.

\subsection{Analysis on the effect of $p H$}

As can be seen from Table 2, the $k$ value at $\mathrm{pH} 4$ is smaller than that at $\mathrm{pH} 6$. This indicates that the mass transfer coefficient measured in the limestone dissolution experiment is not the physical mass transfer coefficient. The reason for such effect of $\mathrm{pH}$ on the $k$ value is that the mass transfer of $\mathrm{H}^{+}$ions was accompanied by chemical reactions in the mass transfer boundary layer, as a number of investigators have pointed out. Although the actual processes involved are complex, an approximate analysis can be made to explain the effect of $\mathrm{pH}$ on the $k$ value.

We may assume that reaction (1) reaches equilibrium at the surface of limestone and reaction (2) is replaced by the following two reactions

$$
\begin{aligned}
& \mathrm{CO}_{3}^{2-}+\mathrm{H}_{2} \mathrm{O} \rightleftharpoons \mathrm{HCO}_{3}^{-}+\mathrm{OH}^{-} \\
& \mathrm{H}^{+}+\mathrm{OH}^{-} \rightleftharpoons \mathrm{H}_{2} \mathrm{O}
\end{aligned}
$$

due to the low concentration of $\mathrm{H}^{+}$in the vicinity of the surface. Since reaction (14) is instantaneous and water is already available on the surface, reaction (14) can be also assumed to reach equilibrium at the surface. Reaction (15) is instantaneous and its 
equilibrium constant is very large, but $\mathrm{H}^{+}$has to move into the boundary layer from the bulk solution or $\mathrm{OH}^{-}$has to move outward from the surface for their reaction to take place. Thus the actual rate of reaction (15) and the place where the reaction (15) occurs depend on the inward diffusion of $\mathrm{H}^{+}$and the outward diffusion of $\mathrm{OH}^{-}$. Since the reaction of $\mathrm{H}^{+}$with $\mathrm{OH}^{-}$is faster than that with $\mathrm{HCO}_{3}^{-}$, we may assume that at $\mathrm{pH}>4$, the $\mathrm{H}^{+}$ions diffusing into the boundary layer are consumed entirely by the reaction with $\mathrm{OH}^{-}$ions and that the dissolution rate equals the rate of $\mathrm{H}^{+}$or $\mathrm{OH}^{-}$consumption in the boundary layer. Thus, for mass transfer of $\mathrm{H}^{+}$across the boundary layer accompanied with reaction (15), the rate constant $k$ in Eq. (9) can be expressed as [16]

$$
k=k_{\mathrm{H}^{+}}^{0}\left(1+\frac{D_{\mathrm{OH}^{-}}}{D_{\mathrm{H}^{+}}} \frac{\left[\mathrm{OH}^{-}\right]_{\mathrm{s}}}{C_{\mathrm{b}}}\right)
$$

where $k_{\mathrm{H}^{+}}^{0}$ is the physical mass transfer coefficient for $\mathrm{H}^{+} ; D_{\mathrm{OH}^{-}}$and $D_{\mathrm{H}^{+}}$are the diffusivities of $\mathrm{OH}^{-}$and $\mathrm{H}^{+}$, respectively; $\left[\mathrm{OH}^{-}\right]_{\mathrm{s}}$ is the equilibrium concentration of $\mathrm{OH}^{-}$at the surface of limestone. Eq. (16) implies that the penetration depth of $\mathrm{H}^{+}$is smaller than the boundary layer thickness due to the instantaneous reaction between $\mathrm{H}^{+}$ and $\mathrm{OH}^{-}$, thus the apparent mass transfer coefficient $k$ is larger than the physical mass transfer coefficient which is defined by assuming the penetration depth to be the boundary layer thickness. It is obvious that the enhancement factor, the terms in the bracket of Eq. (16), increases with increasing $\mathrm{pH}$, while other experimental variables are kept constant.

The value of $k_{\mathrm{H}^{+}}^{0}$ and enhancement factors can be estimated for the present experimental conditions. According to the diffusivity data given by Chan and Rochelle [3], $D_{\mathrm{OH}^{-}} / D_{\mathrm{H}^{+}}$was determined to be 0.57 . The value of $\left[\mathrm{OH}^{-}\right]_{\mathrm{s}}$ can be estimated from the solubility product of calcite, $K_{\mathrm{sp}}$ [17], and the equilibrium constant of reaction (14), $K_{\mathrm{w}} / K_{2}[18]$ :

$$
\begin{aligned}
& \log K_{\mathrm{sp}}=-8.03-0.01183(T-273) \\
& \log \frac{K_{\mathrm{w}}}{K_{2}}=-\frac{1568.6}{T}-0.4105+0.00673 T .
\end{aligned}
$$

At $60^{\circ} \mathrm{C}$ and $0.1 \mathrm{M} \mathrm{CaCl}_{2}$ solution, the value of $\left[\mathrm{OH}^{-}\right]_{\mathrm{s}}$ was estimated to be $4.9 \times 10^{-6} \mathrm{M}$. Thus, according to Eq. (16), the enhancement factors estimated for $\mathrm{pH} 4$ and 6 are 1.03 and 3.79, respectively. The ratio of these two values, 0.27 , agrees very well with the ratio of the two average measured values of $k, 0.26$. The average value of $k_{\mathrm{H}^{+}}^{0}$ calculated from the two average measured values of $k$ using Eq. (16) is 0.224 $\mathrm{cm} / \mathrm{s}$. These results indicate that under the present experimental conditions, the dissolution rate at $\mathrm{pH} 6$ is greatly enhanced by the chemical reaction of $\mathrm{H}^{+}$with $\mathrm{OH}^{-}$ within the boundary layer, whereas the enhancement at $\mathrm{pH} 4$ is small and the dissolution rate approximates the physical mass transfer rate.

\section{Conclusion}

At the experimental conditions of this study, the dissolution rate of limestone is controlled by the mass transfer of hydrogen ions accompanied with chemical reactions 
in the liquid film surrounding the limestone particle. The dissolution rate constant, being equal to the mass transfer coefficient, increases as the $\mathrm{pH}$ value and the stirrer speed increase, and remains constant as the particle size decreases. The dissolution rate is enhanced mainly by the reaction of $\mathrm{H}^{+}$with $\mathrm{OH}^{-}$within the liquid film; but at $\mathrm{pH} 4$, the enhancement effect is small and the measured rate constant approximates the physical mass transfer coefficient. A model which assumes that the limestone particle dissolves according to shrinking-core behavior, and the mass transfer coefficient is independent of particle size well describes the dissolution kinetics. Although the six limestones have different geological properties and soluble contents, the dissolution rates per unit surface area at the same particle size are the same, i.e. independent of the source of limestone, due to the mass-transfer control kinetics. However, the time taken to reach a certain fraction of dissolution depends on the source and the particle size of limestone since the required time is proportional to the molar concentration of $\mathrm{CaCO}_{3}$ and $\mathrm{MgCO}_{3}$ in the limestone and the initial particle size.

\section{Notation}

$A_{\mathrm{S}} \quad$ total surface area of limestone particles $\left(\mathrm{m}^{2}\right)$

$A_{\text {So }} \quad$ initial value of $A_{\mathrm{s}}\left(\mathrm{m}^{2}\right)$

$C_{\mathrm{b}} \quad$ bulk concentration of hydrogen ion $\left(\mathrm{kg} \mathrm{mol} / \mathrm{m}^{3}\right)$

$C_{\mathrm{s}}^{*} \quad$ equilibrium surface concentration of hydrogen ion $\left(\mathrm{kg} \mathrm{mol} / \mathrm{m}^{3}\right)$

$d \quad$ diameter of limestone particle $(\mathrm{m})$

$D_{\mathrm{H}^{+}} \quad$ diffusivity of hydrogen ion $\left(\mathrm{m}^{2} / \mathrm{s}\right)$

$D_{\mathrm{OH}^{-}}$diffusivity of hydroxyl ion $\left(\mathrm{m}^{2} / \mathrm{s}\right)$

$e \quad$ porosity of limestone

$k \quad$ dissolution rate constant $(\mathrm{m} / \mathrm{s})$

$k_{\mathrm{H}^{+}}^{0} \quad$ physical mass transfer coefficient for hydrogen ion $(\mathrm{m} / \mathrm{s})$

$k_{\mathrm{L}} \quad$ mass transfer coefficient $(\mathrm{m} / \mathrm{s})$

$k_{\mathrm{r}} \quad$ rate constant of surface reaction $(\mathrm{m} / \mathrm{s})$

$K_{2}$ the second ionization constant for carbonic acid $\left(\mathrm{kg}\right.$ ion $\left./ \mathrm{m}^{3}\right)$

$K_{\text {sp }} \quad$ solubility product $\left(\mathrm{kg} \text { ion } / \mathrm{m}^{3}\right)^{2}$

$K_{\mathrm{w}} \quad$ ion product for water $\left(\mathrm{kg} \text { ion } / \mathrm{m}^{3}\right)^{2}$

$m$ total moles of $\mathrm{CaCO}_{3}$ and $\mathrm{MgCO}_{3}$ in solid phase $(\mathrm{kg} \mathrm{mol})$

$m_{0} \quad$ initial total moles of $\mathrm{CaCO}_{3}$ and $\mathrm{MgCO}_{3}$ in solid phase (kg mol)

$R \quad$ radius of limestone particle $(\mathrm{m})$

$R_{0} \quad$ initial radius of limestone particle (m)

$\mathrm{Sg} \quad$ specific surface area of limestone $\left(\mathrm{m}^{2} / \mathrm{kg}\right)$

$t \quad$ time (s)

$T \quad$ temperature (K)

$X \quad$ fraction of dissolved limestone

\section{Greek letters}

$\rho_{\mathrm{b}} \quad$ bulk density of limestone $\left(\mathrm{kg} / \mathrm{m}^{3}\right)$

$\rho_{\mathrm{m}} \quad$ molar concentration of $\mathrm{CaCO}_{3}$ and $\mathrm{MgCO}_{3}$ in limestone $\left(\mathrm{kg} \mathrm{mol} / \mathrm{m}^{3}\right)$

$\omega \quad$ stirrer speed (rpm) 


\section{References}

[1] L.N. Plummer, D.L. Parkhurst, T.M.L. Wigley, ACS Symp. Ser. 93 (1979) 538.

[2] D.C. Drehmel, Proceedings of the Second International Lime/Limestone Wet-Scrubbing Symposium vol. 11972, pp. 167-194, US EPA, APTD-1161.

[3] P.K. Chan, G.T. Rochelle, ACS Symp. Ser. 188 (1982) 75.

[4] A.J. Toprac, G.T. Rochelle, Environ. Prog. 1 (1982) 52.

[5] C.L. Gage, G.T. Rochelle, J. Air Waste Manage. Assoc. 42 (1992) 926.

[6] N. Ukawa, T. Takashina, N. Sinoda, Environ. Prog. 12 (1993) 238.

[7] J. Ahlbeck, T. Engman, M. Vihma, Chem. Eng. Sci. 48 (1993) 3479.

[8] J. Ahlbeck, T. Engman, M. Vihma, Chem. Eng. Sci. 50 (1995) 1081.

[9] P.V. Danckwerts, Gas-Liquid Reactions, McGraw-Hill, New York, 1970.

[10] M. Wallin, I. Bjerle, Chem. Eng. Sci. 44 (1989) 61.

[11] P.H. Calderbank, M.B. Moo-Yang, Chem. Eng. Sci. 16 (1961) 39.

[12] P. Harriott, AIChE J. 8 (1962) 93.

[13] P.L.T. Brian, H.B. Hales, T.K. Sherwood, AIChE J. 15 (1969) 727.

[14] D.M. Levins, J.R. Glastonbury, Trans. Inst. Chem. Eng. 50 (1972) 132.

[15] A.S. Foust, Principles of Unit Operations, 2nd edn., Wiley, New York, 1980.

[16] D.R. Olander, AIChE J. 6 (1960) 233.

[17] O. Söhnel, J. Garside, Precipitation: Basic Principles and Industrial Applications, Butterworth-Heinemann, Oxford, 1992.

[18] H.S. Harned, B.B. Owen, The Physical Chemistry of Electrolyte Solutions, 2nd edn., Reinhold, New York, 1950. 